\title{
LA CUESTIÓN SOCIAL DESDE LA RERUM NOVARUM HASTA LA OCTOGESIMA ADVENIENS
}

\author{
Carla Maria Bio Gaidolfi \\ Universidad Católica Sedes Sapientiae \\ carlabio@ucss.edu.pe
}

Fecha de recepción: agosto de 2014 Fecha de aceptación: octubre de 2014

ReSUMEN: En el presente artículo se efectúa un breve estudio de los documentos pontificios que abordan el tema de la denominada «cuestión social» dentro de la Doctrina Social de la Iglesia, empezando por la carta encíclica Rerum novarum del papa León XIII, hasta la carta apostólica Octogesima adveniens del papa Pablo VI. El enfoque de la presente investigación es cualitativo, de alcance descriptivo y de diseño no experimental. Está estructurado en dos capítulos. En el primer capítulo, se efectúa una breve descripción sobre lo que se entiende como Doctrina Social de la Iglesia, con el fin de poder introducir al lector dentro del contexto del tema central. El segundo capítulo desarrolla el tema central del trabajo; esto es el análisis de los principales documentos pontificios que plantean el tema de la "cuestión social» durante los pontificados de los papas León XIII, Pío XI, Pío XII, Juan XXIII y Pablo VI. Se empieza con el análisis de la que es considerada la

* Carla María Bio Gaidolfi es licenciada en Derecho y Ciencias Políticas por la Universidad de Lima. Es egresada de la Maestría en Persona, Familia y Sociedad a la Luz de la Doctrina Social de la Iglesia en la Escuela de Postgrado de la Universidad Católica Sedes Sapientiae (UCSS). Es docente ordinario de esa misma casa de estudios. Es Jefa de la Oficina de Personal y Asuntos Legales de la UCSS. 
Carta Magna de la cuestión social, la encíclica Rerum novarum, promulgada por el papa León XIII en 1891, llegando hasta el análisis de la carta apostólica Octogesima adveniens, promulgada por el papa Pablo VI en 1971. Veremos que los principios establecidos por el papa León XIII en la encíclica Rerum novarum permanecen en el tiempo y han sido tomados por los pontífices posteriores como base para la actualización de la Doctrina Social de la Iglesia en temas sociales. Veremos, igualmente, que una de las principales reacciones suscitadas ante la crítica directa efectuada por León XIII contra la situación del trabajo obrero fue el nacimiento de una rama autónoma del derecho, que no existía con anterioridad: el derecho laboral.

Palabras clave: Cuestión social, papas, encíclicas, trabajo, remuneración, sindicato.

\section{THE SOCIAL QUESTION SINCE THE RERUM NOVARUM UNTIL OCTOGESIMA ADVENIENS}

Aвstract: In this article a brief study of papal documents that address the point of the so-called «social issue» within the Social Doctrine of the Church takes place, beginning with the Encíclica Rerum Novarum of Pope Leo XIII Carta Apostólica Octogesima Adveniens of Pope Paul VI. The focus of this research is qualitative, descriptive and of non-experimental design. This article is divided into two chapters. In the first chapter a brief description of what is understood as Social Doctrine of the Church, in order to introduce the reader within the context of focus is performed. The second chapter develops the theme of the work, ie the analysis of the main papal documents that raise the issue of a «social issue» during the pontificates of Popes Leo XIII, Pius XI, Pius XII, John XIII and Paul VI. It starts with the analysis of which is considered the Magna Carta of the social question, the Encíclica 
Rerum Novarum, issued by Pope Leo XIII in 1891, reaching the analysis of the Carta Apostólica Octogesima Adveniens, promulgated by Pope Paul VI in 1971. Throughout this analysis we see that the principles established by Pope Leo XIII in the Encíclica Rerum Novarum remain in time and have been taken by later pontiffs as the basis for updating the Social Doctrine of the Church on social issues. We shall also see that one of the main reactions raised against direct criticism made by Leo XIII against workman situation was the birth of an autonomous branch of law that did not exist before: labour law.

KeYwords: Social Question, Popes, Encíclicas, Work, Remuneration, Union.

\section{INTRODUCCIÓN}

1 presente artículo nace de la pregunta sobre la posición de la Iglesia respecto al tema del trabajo. Para responder a esta interrogante es necesario viajar en el tiempo y ubicarse dentro del contexto histórico del gran cambio que significó la revolución industrial de fines del siglo XIX en el mundo. El desarrollo de la ciencia y de la técnica trajo consigo un aumento de la riqueza, pero esto implicó también que el trabajo agrícola y el artesano, fuentes de sustento hasta ese entonces, se dejaran de lado. Consecuencia de la revolución industrial fue también el abandono del campo y la migración a las ciudades. Los empresarios, entonces, a partir de la premisa de obtener riqueza, abusaban de los trabajadores al imponer jornadas de trabajo interminables y remuneraciones miserables. 
En el presente artículo se analiza, en un breve resumen, cuál ha sido y cuál es la posición de la Iglesia frente al tema del trabajo, empezando con la carta encíclica Rerum novarum, promulgada por el papa León XIII en 1891, en respuesta a los abusos cometidos contra la gran masa de asalariados al inicio de la revolución industrial, abusos que llevaron al Sumo Pontífice a levantar su voz y denunciar ante el mundo los maltratos a los que eran sometidos los trabajadores asalariados. Luego, se analizan los documentos pontificios posteriores que tratan también sobre el tema del trabajo, los cuales han sido publicados por los Papas en ocasión de conmemorarse algún aniversario de la Rerum novarum: (a) encíclica Quadragesimo anno, del papa Pío XI; (b) el discurso La Solennitá radiomensaje del papa Pío XII; (c) la encíclica Mater et Magistra, del papa Juan XIII; (d) la constitución apostólica Gaudium et Spes, fruto del Concilio Vaticano II; (e) la encíclica Populorum progressio y (f) la carta apostólica Octogesima adveniens. Estas últimas fueron propuestas por Pablo VI.

Por otro lado, se abarca con esto un periodo de tiempo de ochenta años desde la publicación de Rerum novarum. Esta es considerada por muchos como la Carta Magna del trabajo. Con ello, se busca determinar la posición de la Iglesia en las cuestiones relacionadas con el trabajo.

\section{BREVES APUNTES SOBRE LA DOCTRINA SOCIAL DE LA IGLESIA}

La enseñanza social de la Iglesia se origina del encuentro del mensaje evangélico y sus exigencias éticas con los problemas que surgen en la vida de la sociedad (Cf. Congregación para la Educación Católica [CEC] 1988: 9). Contiene un cuerpo de doctrina que se articula a medida que la Iglesia interpreta los acontecimientos a lo largo de la historia, a la luz del conjunto 
de la Palabra revelada por Cristo Jesús y con la asistencia del Espíritu Santo (Cf. Catecismo de la Iglesia Católica [CCE] 2422). La Doctrina Social de la Iglesia (DSI) propone principios de reflexión, extrae criterios de juicio y da orientaciones para la acción (Cf. CCE 2423). En ese sentido, posee dos características: (a) la continuidad y (b) la renovación.

Es una doctrina constante, que no depende de diversas ideologías, culturas u opiniones, sino que manifiesta la continuidad de una enseñanza que sostiene sus fundamentos en los valores universales que derivan de la Revelación y de la naturaleza humana. Pero, por otro lado, atenta a los eventos que se producen en la historia, y dejándose interpelar por ellos, la DSI manifiesta una capacidad de renovación continua. Por tanto, la firmeza de los principios de la DSI no la convierten en un sistema rígido de enseñanzas, sino más bien en un Magisterio que está en condiciones de abrirse a las cosas nuevas, sin diluirse en ellas (Compendio de la Doctrina Social de la Iglesia 85$){ }^{1}$

En su continua atención por el hombre y la sociedad, la Iglesia ha acumulado un rico patrimonio doctrinal. Este, al tener sus raíces en la Sagrada Escritura, en especial en el Evangelio y en los escritos apostólicos, ha ido tomando cuerpo y forma a partir de los Padres de la Iglesia y de los grandes Doctores del Medioevo. En este sentido, constituye una doctrina en la cual la Iglesia se ha ido reconociendo progresivamente (Cf. C 87). Como indica el Cardenal Angelo Sodano, en la carta que antecede a la introducción al Compendio, a lo largo de su historia y particularmente durante los últimos cien años, la Iglesia no ha renunciado nunca a decir la "palabra que le corresponde» — según la expresión del Papa León XIIIacerca de las cuestiones de la vida social (C, p. XII).

1 En adelante, Compendio y C para su abreviación en las citas. 
Sin embargo, la locución doctrina social es relativamente moderna, ya que se remonta al papa Pío XI, quien utiliza dicha locución en la carta encíclica Quadragesimo anno, que fue promulgada en 1931 conmemorando el $40 .^{\circ}$ aniversario de la promulgación de la encíclica Rerum novarum. Posteriormente, el papa Pío XII habló de doctrina social católica en su radiomensaje por el 50. aniversario de la encíclica Rerum novarum en 1941 y de doctrina social de la Iglesia en la exhortación apostólica Menti nostrae, de setiembre de 1950 (Cf. C 87).

\section{DESDE LEÓN XIII HASTA PABLO VI}

\subsection{Leon XIII (20.02.1878-20.07.1903)}

En el siglo XIX se produce el encuentro entre el Evangelio y la sociedad industrial moderna. Este se da en los siguientes aspectos: (a) sus nuevas estructuras para producción de bienes de consumo, (b) su nueva concepción de la sociedad, del Estado y de la autoridad y (c) sus nuevas formas de trabajo y de propiedad (Cf. CCE 2421).

La revolución industrial planteó a la Iglesia un gran desafío, ya que durante siglos su mensaje se dirigió a una sociedad de tipo agrícola, caracterizada por ritmos regulares y cíclicos. Ahora debía tomar en cuenta el hecho de que la sociedad se había vuelto más dinámica, debía considerar la complejidad de los nuevos fenómenos y de las increíbles transformaciones que la técnica había hecho posibles.

La denominada cuestión obrera, es decir, el problema de la explotación de los trabajadores debido a la nueva organización industrial del trabajo de matriz capitalista y el problema no menos grave de la instrumentalización ideológica (socialista y comunista) de las justas reivindicaciones del mundo 
del trabajo se convirtieron en un punto de atención urgente para la solicitud pastoral de la Iglesia (Cf. C 267). Las res novae, conformadas por aquellos eventos, constituían un desafío para sus enseñanzas. Es así que el 15 de mayo de 1891, el papa León XIII promulga la primera encíclica social, la Rerum novarum (RN), en la que examina la situación de los trabajadores asalariados. En la introducción de dicho documento, el Papa indica claramente los motivos de su pronunciamiento:

[...] los adelantos de la industria y de las artes, que caminan por nuevos derroteros; el cambio operado en las relaciones mutuas entre patronos y obreros; la acumulación de las riquezas en manos de unos pocos y la pobreza de la inmensa mayoría; la mayor confianza de los obreros en sí mismos y la más estrecha cohesión entre ellos, juntamente con la relajación de la moral, han determinado el planteamiento de la contienda. Cuál y cuán grande sea la importancia de las cosas que van en ello, se ve por la punzante ansiedad en que viven todos los espíritus [...]. (RN 1)

El Sumo Pontífice continúa indicando que habiéndose disuelto los antiguos gremios de artesanos y no habiendo sido llenado dicho vacío por las instituciones públicas, en el transcurso del tiempo los trabajadores fueron quedando cada vez más a merced de la inhumanidad de los empresarios y la codicia de los competidores. Por ello, considera urgente proveer de manera oportuna al «bien de las gentes de condición humilde, pues es mayoría la que se debate indecorosamente en una situación miserable y calamitosa» (RN 1). Asimismo, prosigue señalando que debe tomarse en cuenta que la contratación del trabajo se halla sometida «al poder de unos pocos, hasta el punto de que un número sumamente reducido de opulentos y adinerados 
ha impuesto poco menos que el yugo de la esclavitud a una muchedumbre infinita de proletarios» (RN 1).

Afirma, igualmente, que los intentos de los hombres por mejorar la situación serán inútiles en ese sentido si se deja de lado a la Iglesia (Cf. RN 12). La razón es que esta es la que toma del Evangelio las enseñanzas por las que se puede resolver por completo el conflicto o hacerlo más soportable. Con ello, busca que los órdenes sociales se alíen de la mejor manera posible para mirar por el bien de la causa obrera.

León XIII establece, en primer lugar, que se debe respetar la condición humana. Señala que entre los hombres hay, por naturaleza, muchas y grandes diferencias. No todos tienen iguales talentos, habilidades, salud o fuerzas (Cf. RN 13).

También, considera un error la suposición de que una clase social sea enemiga de la otra, y que los ricos y los pobres deban estar en un "perpetuo duelo». Señala que ambos se necesitan, ya que «ni el capital puede subsistir sin el trabajo, ni el trabajo sin el capital» (RN 14). León XIII indica que la fuerza de la doctrina cristiana puede unir a los ricos y los proletarios, «llamando a ambas clases al cumplimiento de los deberes respectivos y, ante todo, a los deberes de justicia» (RN 15).

Por otro lado, sostiene que el Estado debe tutelar en el obrero los bienes del alma, ya que la vida mortal no es el fin último por el cual hemos sido creados, sino «el camino y el instrumento para perfeccionar la vida del alma» (RN 30). En este sentido, el Papa establece la necesidad de que los trabajos se interrumpan en los días festivos, sin entender que este descanso se refiere a una mayor inoperatividad u ociosidad por parte de los trabajadores. Esta es vista como «engendradora de vicios y fomentadora de derroches de dinero». En cambio, lo que propone el Sumo Pontífice es el «descanso consagrado por la religión», el cual «aparta al hombre de los 
trabajos y problemas de la vida diaria, para atraerlo al pensamiento de las cosas celestiales y a rendir a la suprema divinidad el culto justo y debido».

Además, el sucesor de Pedro enfatiza lo que respecta a los bienes del cuerpo. Lo primero que se ha de hacer es librar a los obreros de la «crueldad de los ambiciosos». No se debe, por tanto, tolerar la exigencia de un rendimiento físico que haga que el cuerpo se rinda por la fatiga y el espíritu se embote por el exceso de trabajo. En ese sentido, León XIII indica que se debe velar porque la jornada diaria no se prolongue por más horas de las que las fuerzas lo permitan. Sin embargo, aclara que la duración del intervalo dedicado al descanso lo determina la clase de trabajo, así como las circunstancias de tiempo y lugar y las condiciones de los operarios (Cf. RN $31)$.

En cuanto al trabajo infantil y al de la mujer también expone sus ideas. Señala que se debe cuidar que los niños hayan desarrollado suficientemente su cuerpo, su inteligencia y su alma antes de que entren en los talleres, toda vez que la actividad precoz destruye la constitución del niño. Respecto a la mujer, considera que esta ha nacido para las labores domésticas, las cuales protegen el decoro femenino, pero sobre todo responden por naturaleza a la educación de los hijos y a la prosperidad de la familia. En ese sentido, señala que hay oficios que son menos aptos para la mujer (Cf. RN).

León XIII considera como un asunto de la mayor importancia lo referente a la cuantía del salario: debe ser suficiente para alimentar a un obrero frugal y morigerado. Asimismo, define las características del trabajo: (a) personal y (b) necesario. En cuanto a la primera, se refiere a que la energía operante es inherente y propia de la persona que la ejerce. En cuanto a la segunda, asevera lo mencionado por cuanto el fruto del trabajo es necesario para el hombre en la defensa de su vida, y la posibilidad de lograr dicho 
sustento se lo da «nada más que el sueldo ganado con su trabajo» (Cf. RN 32).

En lo que se relaciona a las asociaciones de obreros, el Papa manifiesta que son muy convenientes, pero también señala con preocupación que se ha confirmado que dichas asociaciones están siendo manejadas por «jefes ocultos». Estos, anota, imponen una disciplina que no es conforme con lo cristiano ni con la salud pública y acaparan las fuentes de producción, llevando por consiguiente a la miseria a quienes no quieren asociarse con ellos. Por ende, los obreros cristianos se ven ante la alternativa o de inscribirse en dichas asociaciones, peligrosas para su religión, o juntarse para constituir sus propias sociedades y así tratar de liberarse de esa injusta e insoportable opresión (Cf. RN 37).

En este sentido, León XIII establece como ley general y perpetua que las asociaciones de obreros deben constituirse y gobernarse de manera de proporcional los medios más idóneos y convenientes para el fin que se proponen. Este consiste en que cada miembro consiga, en la medida de lo posible, un aumento de los bienes del cuerpo, del alma y de la familia. Mas, aclara el Papa, es evidente que el fin principal de estas asociaciones es buscar la perfección de la piedad y de las costumbres; de lo contrario degenerarían en ese tipo de asociaciones en las que no cuentan para nada las razones religiosas (Cf. RN 39).

Por último, señala que las asociaciones de obreros deben procurar que en ningún momento falte trabajo al obrero. Asimismo, propone que se establezca una aportación con la que poder sostener a las necesidades de estos. Los casos de necesidad pueden ser los siguientes: (a) accidentes de la industria o por enfermedad, (b) vejez y (c) en cualquier otro infortunio. 
Las orientaciones expresadas en $R N$ reforzaron el compromiso cristiano en la vida social, el que se manifestó en el nacimiento y consolidación de numerosas iniciativas de alto nivel civil. Estas son las que siguen: (a) uniones y centros de estudios sociales, (b) asociaciones, (c) sociedades obreras, (d) sindicatos, (e) cooperativas, (f) bancos rurales, (g) aseguradoras, (h) obras de asistencia. Todo esto dio un notable impulso a la legislación laboral en orden a la protección de los obreros, sobre todo de los niños y de las mujeres; a la instrucción y a la mejora de los salarios y de la higiene (Cf. C 268).

La importancia que tiene $R N$ es tal que ha sido considerada por muchos como la carta magna cristiana del trabajo. Además, no solo ha servido de referencia cronológica para posteriores pronunciamientos de la Iglesia respecto al tema del trabajo, sino también como una fuente de inspiración para nuevos desarrollos y para mantener a la Iglesia constantemente en sintonía con los grandes problemas del siempre cambiante mundo del trabajo (Cf. Cornejo 1983: 5-13). En efecto, todos los pronunciamientos de los Sumos Pontífices en relación con el trabajo, efectuados con posterioridad a $R N$, se han dado con ocasión de un nuevo aniversario de la promulgación de dicha encíclica.

\subsection{Pío XI (12.02.1922-10.02.1939)}

Cuarenta años después de la promulgación de Rerum novarum, el desarrollo de la sociedad industrial había llevado a una creciente concentración de fuerza y de poder en el mundo económico-social, y encendido una cruel lucha de clases. A la industrialización se había agregado la expansión del poder de los grupos financieros en un ámbito nacional e internacional. Nos encontramos en el período posterior a la Primera Guerra Mundial, durante 
el cual se estaban afirmando en Europa los regímenes totalitarios. A ello, hay que añadir que en 1929 se había producido una grave crisis económica a nivel mundial (Cf. C 91).

La Iglesia se enfrentaba en ese momento a una sociedad que debía reconstruirse desde sus bases económicas, toda ella convertida en la cuestión que se debía afrontar. Ante esta situación y conmemorando el cuadragésimo aniversario de $R N$, el papa Pío XI promulga en 1931 la encíclica Quadragesimo anno (QA). En ella señala que la peculiaridad de $R N$ es el haber dado al género humano las normas más seguras para resolver de manera adecuada ese «difícil problema de humana convivencia que se conoce bajo el nombre de "cuestión social"»(QA 2).

Igualmente, el Papa sostiene que la finalidad de la encíclica es recordar los grandes bienes que han seguido de $R N$ para toda la sociedad humana. Asimismo, el objetivo es tener presente la defensa ante ciertas dudas a la doctrina surgida de León XIII. Por último, descubriendo la raíz del presente desorden social, tiene el fin de mostrar al mundo el único camino de restauración salvadora, que es la reforma cristiana de las costumbres (Cf. QA 15).

Pío XI menciona, entre los beneficios de la encíclica $R N$, que a partir de las enseñanzas de León XIII se cuidase de elevar a la clase obrera. Esta, «a consecuencia del enorme progreso de las industrias modernas, no había logrado todavía un puesto o grado equitativo en el consorcio humano y permanecía por ello, poco menos que olvidada y menospreciada» (QA 23). En este sentido, el Papa sostiene que es una labor constante, la cual ayudó a dar a conocer a los obreros su verdadera dignidad y también a capacitarlos en el conocimiento de sus deberes y derechos como tales, convirtiéndolos incluso en guías de los demás. 
Otro de los beneficios de $R N$, indica el papa Pío XI, es que impulsó a los pueblos a fomentar intensamente y a poner en práctica verdaderas políticas sociales (Cf. QA 27). Surgió, por ende, una nueva y anteriormente desconocida rama del derecho, la cual defiende firmemente los derechos de los trabajadores, emanados de su dignidad de hombres y de cristianos, tomando con sus leyes, bajo su protección, el alma, la salud, el vigor, la familia, la casa, el lugar de trabajo, la condición de los asalariados y cuanto corresponde a las mujeres y a los niños (Cf. QA 28). Pero aclara que si bien estas leyes no siempre se adaptan a las enseñanzas de León XIII, tienen muchos puntos que saben fuertemente a $R N$.

Respecto a las asociaciones de obreros, las normas dadas por León XIII, según Pío XI, incitaron a los trabajadores a constituir asociaciones profesionales guiándolas por el camino del deber (QA 31). Estas asociaciones de trabajadores prosperaron por todas partes, englobando una gran multitud de obreros, y siendo capaces de defender poderosamente los derechos y los legítimos postulados de los obreros católicos; imponiendo, incluso, a la sociedad los «saludables principios cristianos» (QA 36).

En el numeral 59 de $Q A$, el Papa asevera que el fin de León XIII era conseguir con la $R N$ la redención del proletariado. En muchos casos, empero, dichas enseñanzas fueron dejadas de lado, ya sea por conveniencia o por considerarlas irrealizables. Cuarenta años después, indica el Pontífice, la condición de los trabajadores ha mejorado y se ha hecho más equitativa, sobre todo en las naciones cultas, en que los obreros «no pueden ser ya considerados por igual afligidos por la miseria o padeciendo escasez» (QA 59). Sin embargo, el desarrollo de las artes mecánicas y la industria ha abarcado regiones muy extensas, haciendo crecer inmensamente el número de proletarios necesitados. Por otro lado, los asalariados rurales están bajo 
ínfimas condiciones de vida, por lo que hay que aplicar los oportunos y eficaces remedios de $R N$.

Respecto al salario justo, Pío XI considera que la cuantía del mismo debe fijarse por varios factores y no por uno solo (Cf. QA 66). Señala, además, que el trabajo no puede ser valorado justamente ni remunerado equitativamente sin tomar en cuenta su doble carácter de social e individual (Cf. QA 69). El Papa señala que hay tres puntos a tomar en cuenta para regular y determinar el salario: (a) el sustento del obrero y su familia, (b) la situación de la empresa y (c) la necesidad del bien común.

La remuneración del obrero debe alcanzar tanto paro su sustento como para el de su familia. Sin embargo, esto no se refiere a que el resto de la familia no contribuya en el sostenimiento común de todos, sino que está establecido así en el sentido de que no se debe abusar de la condición de los niños ni de la mujer (Cf. QA 71). Continúa explicando que es un terrible abuso que las madres de familia deban buscar un trabajo remunerado fuera de sus hogares debido a la cortedad del sueldo del padre; debiendo abandonar sus deberes domésticos y, sobre todo, la educación de los hijos. Por lo tanto, concluye el Papa, hay que luchar con denuedo para que los "padres de familia reciban un sueldo lo suficientemente amplio para atender convenientemente las necesidades domésticas ordinarias» (Cf. QA 71).

No obstante, continúa el Pontífice, para establecer la cuantía del salario también es importante tomar en cuenta las condiciones de la empresa y del empresario. Ello es así porque sería injusto exigir a la empresa pagar salarios elevados que no podría soportar, y por ende la llevarían a la ruina junto con sus obreros (Cf. QA 72). Igualmente, Pío XI señala que la cuantía del salario debe «acomodarse al bien público económico» y que es necesario que se dé oportunidad de trabajar a quienes pueden y quieren hacerlo. La justicia social pide que los salarios se fijen de tal modo que haya trabajo 
para el mayor número de personas y que puedan percibir una remuneración suficiente para el sostenimiento de su vida (Cf. QA 74).

Respecto a las asociaciones de obreros, se plantea la libertad de formarlas. Así, $Q A$ dice que el «hombre es libre no sólo para fundar asociaciones de orden y derecho privado sino también para elegir aquella organización y aquellas leyes que estime más conducentes al fin que se ha propuesto» (QA 87).

En el numeral 91 de la encíclica, el Pontífice señala que se había iniciado una particular manera de organización sindical y corporativa: el sindicato, y que considera pertinente explicarla brevemente. Indica que se trata de una persona jurídica constituida como tal por la potestad civil, por lo que esta le otorga cierto grado de monopolio al permitir que solamente el sindicato constituido pueda representar los derechos de los obreros o de los patronos. Por ende, solo este estipulará las condiciones sobre la conducción y locación de la mano de obra, así como garantizar los denominados contratos de trabajo. Sin embargo, inscribirse en el sindicato es potestativo y, en ese sentido, se dice que un sindicato es libre, ya que una vez que se forma parte de este, son obligatorios para los miembros el pago de las cuotas sindicales, así como el de otros tipos de aportaciones. Asimismo, «todos están ligados por los contratos de trabajo estipulados por el sindicato jurídico» (QA 92).

El Papa concluye, en el numeral 94, que se puede ver fácilmente que dichas instituciones reportan beneficios. Estos son los que siguen: (a) la colaboración pacífica de las diversas clases, (b) la represión de las organizaciones sociales, (c) la supresión de los desórdenes y (d) una magistratura especial ejerciendo una autoridad moderadora. 


\subsection{Pío XII (02.03.1939-09.10.1958 $)^{2}$}

El Pontificado del papa Pío XII atravesó los difíciles años de la Segunda Guerra Mundial y de la reconstrucción posbélica. Si bien no publicó encíclicas sociales, sus radiomensajes, así como otras importantes intervenciones en materia social, profundizan la reflexión sobre un nuevo orden social, gobernado por la moral y el derecho, y centrado en la justicia y la paz.

El 1 de junio de 1941, durante la solemnidad de Pentecostés, pronunció un discurso conmemorativo con ocasión del quincuagésimo aniversario de la encíclica Rerum novarum, conocido como La Solennitá (LS). En los numerales 5 y 6 de $L S$, Pío XII hace un breve resumen del porqué de $R N$. Dijo, además, que es obligación de la Iglesia, como guardiana del orden sobrenatural cristiano, formar las conciencias, incluso de aquellos llamados a buscar soluciones para los problemas y deberes que la vida social impone. El Pontífice continúa su discurso señalando que el decenio siguiente a la promulgación de la encíclica Quadragesimo anno por Pío XI «ha volcado sus inquietas y oscuras aguas en el piélago de una guerra que puede levantar insospechables olas que batan la economía y la sociedad» (LS 10). Muestra igualmente su preocupación sobre los problemas y asuntos particulares, y tal vez completamente nuevos que la vida social, después del conflicto que está enfrentando a tantos pueblos, presenta para la Iglesia. Señala que en ese momento es imposible determinarlos ni preverlos. Sin embargo, continúa, es conveniente aprovechar el quincuagésimo aniversario de $R N$ con el fin de dar algunos principios directivos morales para la vida social y económica, animados del mismo espíritu de León XIII y desarrollando sus puntos de vista (Cf. LS 11).

2 Para esta parte se ha consultado Melgar Gil 2013: 427 y ss. 
En $L S$, también se hace referencia al deber personal del trabajo impuesto por la naturaleza. Dice el Papa: «Le corresponde y sigue el derecho natural de cada individuo a hacer del trabajo el medio para proveer a la vida propia y de los hijos» (LS 19). Por otro lado, hace notar que el deber y el derecho al trabajo son impuestos y concedidos al individuo en primera instancia por la naturaleza, no por la sociedad. De ello concluye que el deber y el derecho de organizar el trabajo pertenecen ante todo «a los inmediatos interesados: patronos y obreros», y que si estos no cumplen con su deber, corresponde al Estado «intervenir en el campo del trabajo y en su división y distribución, según la forma y medida que requiere el bien común debidamente entendido» (LS 19). De todos modos, concluye el Papa, la intervención legítima y benéfica del Estado en el campo del trabajo debe ser tal que en principio salve y respete su carácter personal (LS 21).

\subsection{Juan XXIII (28.10.1958-03.06.1963)}

En la primera década de los años sesenta, el panorama mundial se caracterizaba por la recuperación después de las devastaciones de la Segunda Guerra Mundial. Sin embargo, el papa Juan XXIII encuentra que la cuestión social se está universalizando. Ya no se restringe a la clase obrera, sino que se extiende a todas las clases sociales, a todos los países y a la misma sociedad internacional.

Junto a la cuestión obrera y a la revolución industrial, se presentan los problemas de la agricultura, de las áreas en vías de desarrollo, del incremento demográfico, así como los problemas relacionados con la necesidad de una cooperación económica mundial. Las desigualdades ya no solo se presentan al interno de los países, sino que aparecen ahora en el 
plano internacional y manifiestan cada vez con mayor claridad la situación dramática en la que se encuentra el denominado Tercer Mundo (Cf. C 94).

A pocos meses de su elección, Juan XXIII anunció la convocatoria de un concilio ecuménico y en el discurso de apertura del Concilio Vaticano II, el 11 de octubre de 1962, señaló con claridad la que sería la orientación del Concilio. No se trataba de definir nuevas verdades, sino de exponer la doctrina tradicional de una forma más adaptada a la sensibilidad moderna. ${ }^{3}$

El 15 de mayo de 1961, con motivo del septuagésimo aniversario de $R N$, publica la encíclica Mater et Magistra (MM) sobre el reciente desarrollo de la cuestión social a la luz de la doctrina cristiana. En la Introducción, el Papa hace notar que a pesar del tiempo transcurrido desde la publicación de $R N$ su influencia se mantiene de forma vigorosa. Esto es en los documentos de los Sumos Pontífices que han sucedido a León XIII, así como en la organización pública de no pocas naciones (Cf. MM 9).

El papa Juan XXIII señala que veinte años después de la conmemoración efectuada por Pio XII, a los setenta años de promulgada la encíclica $R N$, el estado de cosas ha sufrido profundas transformaciones. Esto se ha dado tanto al interior de los países como en la esfera de las relaciones mutuas (Cf. MM 46).

Así, en el campo científico, técnico y económico se ha descubierto la energía atómica y sus progresivas aplicaciones tanto en lo militar como en lo civil. Se pueden mencionar las siguientes: (a) la química ha descubierto posibilidades casi ilimitadas en el campo de las producciones sintéticas; (b) la automatización se ha extendido, especialmente en el sector industrial y de servicios; (c) la agricultura se ha modernizado progresivamente; casi han desaparecido las distancias entre los pueblos, principalmente por obra

3 Disponible en La Santa Sede. <http://www.vatican.va/news_services/liturgy/saints/ns_ lit_doc_20000903_john-xxiii_it.html>. Consulta hecha en 14.06.2014. 
de la radio y la televisión, y (d) los transportes de toda clase son cada vez más veloces y ya se ha iniciado la conquista de los espacios interplanetarios. Por otro lado, en el campo social, en los movimientos sindicales hay una mayor conciencia de la responsabilidad de los obreros ante los problemas económicos y sociales más importantes (Cf. MM 48).

Sin embargo, indica el Sumo Pontífice, simultáneamente a estos avances puede advertirse que el gran incremento económico y social experimentado por un creciente número de naciones ha acentuado cada día más los evidentes desequilibrios. Estos existen no solo al interior de cada país, sino en el plano mundial, entre los países de distinto desarrollo económico. Por lo tanto, Juan XXIII juzga necesaria la publicación de la $M M$ para, de acuerdo con los cambios de la época, subrayar y aclarar con mayor detalle las enseñanzas de sus predecesores, así como exponer con claridad el pensamiento de la Iglesia sobre los nuevos y más importantes problemas del momento (Cf. MM 50).

Para Juan XXIII una de las características resaltantes de la época es el incremento de las relaciones sociales. Se entiende como tales a la progresiva multiplicación de las relaciones de convivencia, con la consiguiente formación de variadas formas de vida y de actividad asociada. Los factores que han contribuido a la existencia de este hecho, según el Papa son, entre otros, los que siguen: (a) el progreso científico y técnico, (b) el aumento de la productividad económica y (c) el auge del nivel de vida del ciudadano (Cf. MM 59).

En opinión del llamado Papa bueno, este progreso de las relaciones sociales trae consigo numerosas ventajas y beneficios. Permite la mejor satisfacción de muchos derechos de la persona humana, en especial, los denominados económico-sociales, que atienden fundamentalmente a 
las exigencias de la vida humana. Entre estos se pueden mencionar los siguientes: (a) el cuidado de la salud, (b) instrucción básica más profunda y extensa, (c) formación profesional más completa, (d) vivienda, (e) trabajo, (f) descanso conveniente y (g) recreación honesta (Cf. MM 61).

No obstante, advierte que, junto con la multiplicación y desarrollo de estas formas de asociación, en muchos sectores de la actividad humana, la regulación y la definición jurídicas de las diversas relaciones sociales se vuelven más detalladas y, consiguientemente, el radio de acción de la libertad individual se reduce. Sin embargo, aclara que el aumento de las relaciones sociales no hará necesariamente de los hombres «simples autómatas sin libertad propia» (MM 62), ya que este progreso debe verificarse de forma que "proporcione a los ciudadanos el mayor número de ventajas y evite, o a lo menos aminore, los inconvenientes» (MM 64).

En lo que respecta a la situación del trabajo (Cf. MM 68), señala que a los trabajadores se les remunera con salarios tan bajos que quedan sometidos, ellos y sus familias, a condiciones de vida totalmente infrahumanas. Este hecho lo atribuye a que en las naciones en que esta situación se presenta, la industrialización está en sus comienzos o no suficientemente desarrollada, presentándose inclusive la situación de que frente a la extrema pobreza de la mayoría, unos pocos ostentan de manera abierta e insolente la abundancia y el lujo desenfrenados. A esto añade el Papa que se observa, en las naciones económicas más desarrolladas, que el trabajo de categorías enteras de trabajadores honrados y diligentes, es retribuido con salarios demasiado bajos, insuficientes para cubrir las necesidades de vida (Cf. MM 70).

Por otro lado, en materia de fijación de salario, el Sumo Pontífice sostiene que deben guardarse «a toda costa las normas de la justicia y la equidad». En ese sentido, continúa, en el numeral 71 de la $M M$, es necesario que los trabajadores perciban un salario cuyo monto les permita mantener 
un nivel de vida verdaderamente humano. Con ello, podrán hacer frente con dignidad a sus obligaciones familiares.

En relación con la determinación de la remuneración justa del trabajo, Juan XXIII plantea que deben tomarse en cuenta algunos puntos. Estos son los siguientes: (a) la efectiva aportación de cada trabajador a la producción económica; (b) la situación financiera de la empresa en que se trabaja; (c) las exigencias del bien común de la respectiva comunidad política, principalmente en orden a obtener el máximo empleo de la mano de obra en toda la nación, y (d) las exigencias del bien común universal, o sea de las comunidades internacionales, diferentes entre sí en cuanto a su extensión y a los recursos naturales de que disponen (Cf. MM 71).

En el numeral 79 de la $M M$, el Papa señala que las naciones deben facilitar el trabajo al mayor número posible de obreros, evitando que se construyan categorías sociales privilegiadas. Deben, igualmente, mantener una adecuada proporción entre los salarios y los precios, haciendo accesible a los ciudadanos los bienes materiales y los beneficios de la cultura. También, propone el suprimir, o al menos limitar, las desigualdades entre los distintos sectores de la economía; así como buscar un equilibrio adecuado entre el incremento económico y el aumento de los servicios generales necesarios. De igual manera, sugiere ajustar sus estructuras de producción a los progresos de las ciencias y la técnica. Finalmente, indica que se debe lograr que el mejoramiento del nivel de vida sirva no solo para la generación presente, sino que prepare un mejor porvenir para las generaciones futuras.

Respecto a las asociaciones de trabajadores, el Papa señala en el numeral 97 que la finalidad de las mismas ya no es movilizar al trabajador para la lucha de clases. Este debe apuntar a estimular la colaboración mediante acuerdos entre las asociaciones de trabajadores y de empresarios. 


\section{5 Pablo VI (21.06.1963-06.08.1978)}

Al asumir el papado, Pablo VI continuó con el Concilio Vaticano II, que había sido convocado por el papa Juan XXIII. Uno de los documentos fruto del Concilio fue la constitución pastoral Gaudium et Spes (GS) sobre la Iglesia en el mundo de hoy. Esta fue publicada el 7 de diciembre de 1965.

\section{Gaudium et Spes}

Respecto al trabajo humano, la $G S$ considera que es superior a los restantes elementos de la vida económica, ya que estos solo tienen el papel de instrumentos. El trabajo humano, en cambio, procede de la persona. Esta «marca con su impronta las cosas de la naturaleza y las somete a su voluntad» (GS 67), y es el medio ordinario de subsistencia tanto para el trabajador como para su familia.

La $G S$ afirma que Jesús, al trabajar con sus propias manos en Nazaret, le dio al trabajo una dignidad eminente. De allí se deriva, por tanto, para todos los hombres el deber de trabajar fielmente. Asimismo, a partir de esto, se entiende su derecho al trabajo. Por ende, es deber de la sociedad, según sus circunstancias, ayudar a los ciudadanos para que puedan encontrar la oportunidad de un «trabajo suficiente» (GS 67).

En lo que se refiere a la fijación de la remuneración del trabajo, el numeral 67 indica que deben tenerse en cuenta tanto el puesto de trabajo y la productividad de cada uno como las condiciones de la empresa y el bien común. Igualmente, señala que la remuneración debe ser tal que permita al «hombre y a su familia una vida digna en el orden material, social, cultural y espiritual». Para ello, esta debe tener presentes el puesto de trabajo y la 
productividad de cada uno, así como las condiciones de la empresa y el bien común.

Indica, además, que el proceso de producción de la actividad económica no debe organizarse ni regularse de modo que cause daño a los trabajadores. Esta tiene que ajustarse a los siguientes aspectos: las necesidades de las personas, su manera de vivir y su vida familiar, especialmente cuando se trata de las madres de familia, y tomando en consideración también el sexo y la edad.

Por otra parte, se espera que el trabajador también disfrute de un tiempo de reposo. Este debe permitir que participe en la vida familiar, cultural, social y religiosa. Asimismo, se considera que la persona desarrolle las energías y cualidades que en su trabajo no pueda impulsar.

La constitución apostólica señala, también, que el derecho de los obreros a fundar libremente asociaciones que representen al trabajador y que colaboren en la recta ordenación de la vida económica es un derecho fundamental de la persona humana. Asimismo, considera tal el derecho de participar libremente en las actividades de dichas instituciones, sin temor a represalias. Por otra parte, respecto a los conflictos laborales, considera a la huelga como un medio extremo para la defensa de los derechos de los trabajadores y la obtención de sus justas aspiraciones. Recomienda encontrar una solución pacífica a los mismos. Esta recurrirá al diálogo conciliatorio (Cf. GS 68).

\section{Populorum progressio}

El 26 de marzo de 1967, el papa Pablo VI promulga la encíclica Populorum progressio (PP) sobre el desarrollo de los pueblos. En ella, el Sumo Pontífice afirma que el hecho más importante de todos, al momento de 
la promulgación del documento, es que la cuestión social ha tomado una dimensión mundial (Cf. PP 3). En el tiempo transcurrido entre la GES y la PP había ido creciendo la toma de conciencia de las diferencias que discriminaban y sometían a situaciones de injusticia y marginación a muchos países del Tercer Mundo. Dicha situación había hecho estallar los conflictos sociales (Cf. CEC 1988: 28).

En esta encíclica, el Papa presenta al desarrollo como el paso de condiciones de vida menos humanas a condiciones de vida más humanas, señalando sus características. Las situaciones menos humanas se dan cuando hay carencias materiales y morales, y estructuras opresivas. Las situaciones humanas requieren lo siguiente: (a) la posesión de lo necesario, (b) la adquisición de conocimientos y cultura, (c) el respeto a la dignidad de los otros, (d) el reconocimiento de los valores supremos y de Dios, y (e) la vida cristiana de fe, esperanza y caridad (Cf. CEC 1988: 29). Sin embargo, la disparidad en el goce de los bienes y en el ejercicio del poder hace que en algunas regiones la mayoría de la población pobre viva en condiciones de vida y trabajo indignas de la persona humana (Cf. CEC 1988: 28).

Respecto al trabajo, el Papa señala que este ha sido querido $y$ bendecido por Dios. Es Él quien ha dotado al hombre de inteligencia y le ha dado también el modo de acabar Su obra creadora, de modo que, en cierto sentido, todo trabajador es también un creador (Cf. PP 27). No obstante, continúa explicando Pablo VI (Cf. PP 28), el trabajo tiene el peligro de deshumanizar a quien lo lleva a cabo. Indica, igualmente, que el mundo está enfermo y su enfermedad es la falta de fraternidad entre los hombres y entre los pueblos (Cf. PP 66).

En este sentido, insiste en el deber de hospitalidad. A esta la define como deber de solidaridad humana y de caridad cristiana, al que están 
obligadas tanto las familias como las organizaciones culturales de los países que acogen a los extranjeros (Cf. PP 67). Explica que esta debe ofrecerse a los trabajadores emigrantes, que viven muchas veces en condiciones inhumanas, «ahorrando de su salario para sostener a sus familias, que se encuentran en la miseria en su suelo natal» (PP 69).

\section{Octogesima adveniens}

El 14 de mayo de 1971, en el octogésimo aniversario de la encíclica Rerum novarum, el papa Pablo VI promulga la carta apostólica Octogesima adveniens (OA). Dicho documento se dirige al Presidente del Consejo para los Seglares y de la Comisión Pontificia Justicia y Paz, Cardenal Mauricio Roy. El Papa indica que el mensaje de la $R N$ sigue inspirando la acción en favor de la justicia social, y es necesario, por ello, continuar y ampliar sus enseñanzas para responder a las necesidades nuevas de un mundo en transformación (Cf. OA 1). Asimismo, asegura que persisten las flagrantes diferencias en el desarrollo, tanto económico como cultural y político de las naciones, pero por todas partes se aspira a una justicia mayor (Cf. OA 2).

Por otra parte, el Papa señala que la civilización agraria se está debilitando debido al constante avance de la industrialización, lo que ha generado un fenómeno nuevo: la urbanización. El éxodo del campo a la ciudad genera no solo un crecimiento industrial, sino un aumento demográfico continuo en los centros urbanos. Así, la gente del campo migra hacia los suburbios, en donde no encuentran alojamiento ni empleo, sino una condición económica inferior (Cf. OA 8).

Pablo VI hace notar que la humanidad experimenta un nuevo tipo de soledad. Se trata de aquella soledad que se origina cuando se está en 
medio de una «muchedumbre anónima que le rodea y dentro de la cual se siente como extraña» (OA 10).

Respecto al trabajo, el Papa señala que toda persona tiene derecho a este, a una remuneración equitativa que le permita una vida digna para ella y su familia, y a la posibilidad de desarrollar sus cualidades y su personalidad en el ejercicio de su profesión.

De igual manera, en cuanto a la organización hace énfasis en que si bien las sociedades democráticas aceptan a la organización sindical para la defensa de dichos derechos, no siempre están dispuestas a aceptar su ejercicio. Los sindicatos, para el papa Pablo VI, tienen una función importante: (a) la representación de las diversas categorías de trabajadores, (b) su legítima colaboración en el progreso económico de la sociedad y (c) el desarrollo del sentido de sus responsabilidades para la realización del bien común. Mas, también hace notar el Papa que la acción de estos sindicatos no está exenta de dificultades, por la tentación de aprovechar su posición de fuerza para intentar imponer, sobre todo, a través de la huelga, condiciones que pueden ser gravosas para el conjunto de la economía o del cuerpo social, o para tratar de obtener reivindicaciones que tienen más bien carácter político (Cf. OA 14).

El Papa pide tomar en cuenta de manera especial a los trabajadores emigrados. El motivo principal es que su condición de extranjeros hace tanto más difícil toda reivindicación social de su parte, aun cuando participan en el esfuerzo económico del país que los recibe. Debe superarse, en este sentido, cualquier actitud nacionalista, y crearse una legislación que reconozca su derecho a la emigración y favorezca los siguientes aspectos: (a) su integración, (b) su promoción profesional y (c) acceso a un alojamiento decente, donde pueda vivir, si es posible, con su familia (Cf. OA 17). 
Finalmente, el Sumo Pontífice profetiza en esta carta apostólica que el crecimiento demográfico traerá consigo el aumento del número de personas que no encontrarán trabajo y se verán reducidas a la miseria. Esta situación se hará realidad, a no ser que se generen eficaces políticas de inversión, de organización de la producción y de los mercados, así como de formación adecuada, a fin de crear puesto de trabajo (Cf. OA 18).

\section{CONCLUSIONES}

1) La Doctrina Social de la Iglesia manifiesta la continuidad de una enseñanza que tiene sus fundamentos en los valores universales que derivan de la Revelación y de la naturaleza humana. Sin embargo, no es un sistema rígido de enseñanza, ya que se actualiza constantemente, a la luz de los eventos que se producen en el devenir histórico de la humanidad. En tal sentido, la Iglesia no ha renunciado nunca a pronunciarse acerca de las cuestiones sociales.

2) Cuando se produjo la revolución industrial, a finales del siglo XIX, esta trajo consigo un total cambio de concepciones: la forma de ver a la sociedad, al Estado, a la autoridad, e incluso al trabajo, cambió radicalmente. Esto fue un gran desafío para la Iglesia, la cual centró su atención pastoral en la denominada cuestión obrera: la explotación de los trabajadores debido a la nueva organización industrial.

3) La encíclica Rerum novarum, promulgada en 1891 por el papa León XIII, es la primera en examinar la situación de los trabajadores asalariados. Entre otros puntos, este documento denuncia las miserables condiciones de trabajo a la que estaban expuestos los obreros en esa época y señala que es un error considerar que la 
solución está en la denominada lucha de clases. León XIII defiende la necesidad del descanso físico para restaurar no solo las fuerzas físicas del trabajador, sino como tutela de los bienes del alma. Asimismo, critica el trabajo infantil y el trabajo de la mujer. Señala como un asunto de la mayor importancia la fijación de la cuantía del salario, la cual, indica, debe ser suficiente para alimentar a un obrero y a su familia. Considera que las asociaciones de obreros son convenientes, y que su finalidad principal es la de velar por los bienes del cuerpo y el alma de sus miembros y los de sus familias, buscando que nunca falte el trabajo al obrero.

4) La encíclica Rerum novarum fue publicada en una época en que se pensaba que la Iglesia únicamente se preocupaba de predicar resignación a los pobres y caridad a los ricos. En ese sentido, la audacia del papa León XIII, al publicar un documento que atacaba abierta y directamente la raíz del problema obrero, causó diversas reacciones. Una de esas reacciones fue la del nacimiento de una rama autónoma del derecho, no existente hasta ese entonces, que se dedicó a proteger al trabajador y a regular las situaciones surgidas de la relación entre obreros y patronos: el derecho laboral.

5) Pio XI, en su encíclica Quadragesimo anno (1931); Pio XII, en su radiomensaje La Solennitá (1941); Juan XXIII, en su encíclica Mater et Magistra (1961), y en el Concilio Vaticano II con su constitución apostólica Gaudium et Spes (1965); el Papa Pablo VI, en su encíclica Populorum progressio (1967) y en su carta apostólica Octogesima adveniens (1971), analizan la situación de los trabajadores al momento de la dación de dichos documentos pontificios. Cada Papa defiende los siguientes aspectos: (a) el 
criterio de remuneración justa como aquella que es suficiente para mantener al trabajador y a su familia; (b) establecen aquellos criterios que consideran no deben dejarse de lado al momento de establecer la cuantía de la remuneración; (c) critican el trabajo infantil y el trabajo de la mujer por considerar que las aparta de su labor principal que es la de guiar a la familia; (d) apoyan la asociación de los trabajadores bajo los sindicatos, señalando que la principal labor de estos no es la lucha de clases, sino la protección de los trabajadores y sus familias. Asimismo, en el caso de Pablo VI, se manifiesta además la preocupación sobre la situación de los trabajadores emigrantes.

6) Vemos, pues, a lo largo de este análisis, que los principios establecidos por el papa León XIII en la encíclica Rerum novarum permanecen en el tiempo. Es tal su importancia que los pontífices posteriores siempre han tomado dichas enseñanzas como base para la actualización de la Doctrina Social de la Iglesia en temas concernientes a la cuestión social. Todas estas preocupaciones han sido publicadas en documentos pontificios promulgados con ocasión de algún aniversario de la publicación de la que se considera la Carta Magna de la cuestión social. 


\section{REFERENCIAS}

Conferencia Episcopal Peruana

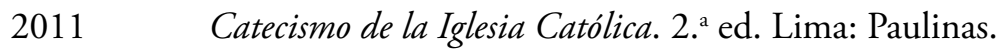

2008 Constitución apostólica Gaudium et Spes. En Concilio Vaticano II. Documentos Completos. Lima: Paulinas, pp. 165-272.

Congregación para la Educación Católica

1988 Orientaciones para el estudio y la enseñanza de la doctrina social de la Iglesia en la formación de los sacerdotes. Roma: Congregación para la Educación Católica.

Cornejo Chavez, Héctor

1983 «Visión Cristiana del Trabajo a lo largo de las Encíclicas Sociales». En Revista de la Universidad Católica, N. 13-14, pp. 5-13.

JUAN XXIII

1961 Encíclica Mater et Magistra. Roma. Disponible en La Santa Sede. <http://www.vatican.va/holy_father/john_xxiii/encyclicals/ documents/hf_j-xxiii_enc_15051961_mater_sp.html>. 
LEÓN XIII

1891 Encíclica Rerum novarum. Roma. Disponible en La Santa Sede. <http://www.vatican.va/holy_father/leo_xiii/encyclicals/ documents/hf_l-xiii_enc_15051891_rerum-novarum_sp.html>.

Melgar Gil, Luis-Tomás

2013 La historia de los Papas desde San Pedro hasta Francisco. Madrid: Libsa.

PABLO VI

1967 Encíclica Populorum progressio. Disponible en La Santa Sede. <http://www.vatican.va/holy_father/paul_vi/encyclicals/ documents/hf_p-vi_enc_26031967_populorum_sp.html>.

1971 Carta Apostólica Octogesima adveniens. Disponible en La Santa Sede. <http://www.vatican.va/holy_father/paul_vi/apost_letters/ documents/hf_p-vi_apl_19710514_octogesima-adveniens_ sp.html>.

PÍO XI

1931 Encíclica Quadragesimo anno. Roma. Disponible en La Santa Sede. <http://www.vatican.va/holy_father/pius_xi/encyclicals/ documents/hf_p-xi_enc_19310515_quadragesimo-anno_ sp.html>. 
PíO XII

1941 Discurso La Solennita. Radiomensaje por la solemnidad de Pentecostés (1941). Disponible en La Santa Sede. <http://www. vatican.va/news_services/liturgy/saints/ns_lit_doc_20000903_ john_xxiii_it.html>. Consulta hecha en 14/06/2014.

Pontificio Consejo Justicia y Paz

2009 Compendio de Doctrina Social de la Iglesia. 2. ${ }^{a}$ reimpresión. Lima: Paulinas. 